over 2,000 subjects. Webster (1962) reported more side-effects from ferrous sulphate taken twice a day than from a similar dose of slow-release ferrous sulphate also taken twice a day. Almost half the subjects he was studying, however, suffered from gastrointestinal irritation or ulcerative colitis, and it is difficult to judge how many of the symptoms were due to underlying disease rather than the iron therapy.

In studies in which radioactive iron has been used to investigate the absorption from slow-release preparations (Bothwell, Pirzio-Biroli, and Finch, 1958 ; Crossland-Taylor, Keeling, and Cromie, 1965) the latter have been shown to be less well absorbed than similar doses of ordinary ferrous sulphate. There is little justification, therefore, for expecting slow-release iron to be more effective in therapy.

The idea of being able to treat patients with a single daily dose is attractive, but it would appear from the present data that no specific benefit is to be derived by using a slow-release preparation.

Ferrous fumarate is less soluble than ferrous sulphate, and in a recent study with ${ }^{59} \mathrm{Fe}$-labelled pills (Callender and Warner, 1969) it was less well absorbed. This would account for the fact that the therapeutic response of the fumarate is similar to that of slow-release ferrous sulphate. A similar daily dose of quickly released ferrous sulphate would be expected to give a better response.

I am grateful to Dr. Violet Anderson, formerly of Glaxo Laboratories, for the supply of coded tablets.

\section{REFERENCES}

Bothwell, T. H., Pirzio-Biroli, G., and Finch, C. A. (1958). Fournal of Laboratory and Clinical Medicine, 51, 24

Brise, H., and Hallberg, L. (1962). Acta Medica Scandinavica, Suppl. No. 376 , p. 59.

Callender, S. T., and Warner, G. T. (1969). British Medical fournal, 4, 532 .

Crossland-Taylor, P., Keeling, D. H., and Cromie, B. W. (1965). Current Therapeutic Research, Clinical and Experimental, 7, 244 Gomez, G. and Gomez, J. (1967). British fournal of Clinical Practice, 21,31 .

Hallberg, L., and Sölvell, L. (1966). Acta Medica Scandinavica, Suppl.

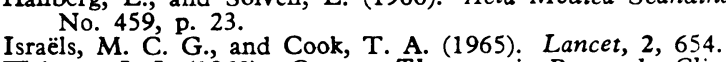

Webster, J. J. (1962). Current Therapeutic Research, Clinical and Experimental, 4,130

Ziehm, D. J., and Likos, J. (1966). Obstetrics and Gynecology, 28, 430.

\title{
Absorption of Therapeutic Preparations of Iron Measured with a Whole Body Counter
}

\author{
SHEILA T. CALLENDER,* M.D., F.R.C.P. ; G. T. WARNER, † D.PHIL.
}

Cummary : The Oxford Whole Body Counter was used ummary : The Oxford Whole Body Counter was used
to measure absorption from various therapeutic preparations of iron in five groups of subjects. Succinic acid enhanced absorption of iron when added to a solution of ferrous fumarate, but not when given with tablets of ferrous fumarate or ferrous sulphate. Ferrous fumarate plus ascorbic acid was absorbed better than ferrous fumarate alone but no better than ferrous sulphate. The addition of ascorbic acid and succinic acid to tablets of ferrous sulphate did not enhance absorption significantly.

\section{Introduction}

Iron-deficiency anaemia is a common condition throughout the world and ferrous sulphate has proved a cheap and effective form of therapy. Nevertheless, new preparations of iron are constantly appearing on the market backed by recommendations which often have not very good foundation. We have used the Oxford Total Body Counter (Warner and Oliver, 1966) to compare the absorption of iron from different therapeutic preparations in individual subjects, and this paper reports our results.

\section{Materials and Methods}

The use of the counter in studies of absorption has been reported elsewhere (Callender, Witts, Warner, and Oliver, 1966).

Forty-four subjects, divided into five groups, were selected for the investigation. The purpose of the study was fully explained to each subject and all agreed to take part. Three subjects were members of the hospital staff and were initially considered to be normal, but one was found to have a serum iron of only $32 \mu \mathrm{g} . / 100 \mathrm{ml}$. The remaining 41 were patients with untreated or partially treated iron deficiency. None had received iron therapy for at least two weeks before the test. In all except six the haemoglobin was $10 \mathrm{~g}$. or more. Groups 1, 2, 3, and 5 (see below) were roughly similar with regard to the degree of anaemia and iron deficiency; the mean haemoglobin values were $11.8,11.7,11.9$, and $11.7 \mathrm{~g} . / 100 \mathrm{ml}$. respectively, and the mean serum iron 46 , 36,46 , and $50 \mu \mathrm{g} . / 100 \mathrm{ml}$. respectively. Subjects in group 4 were on the whole less anaemic and less iron-deficient ; mean haemoglobin $13.8 \mathrm{~g} . / 100 \mathrm{ml}$. and mean serum iron $88 \mu \mathrm{g} . /$ $100 \mathrm{ml}$. (Fig. 1).

Because of the great variability of absorption in different subjects two, or in some instances three, preparations were compared in the same individual by sequential tests, the order of tests being randomized. The total radioactivity retained by any one subject was never more than $0.5 \mu \mathrm{Ci}$.

The subjects were divided into the following groups:

Group 1.-Eight subjects. Iron absorption from a 5 - $\mathrm{ml}$. dose of a syrup containing $140 \mathrm{mg}$. of ferrous fumarate was compared with that from a similar preparation of ferrous fumarate plus $210 \mathrm{mg}$. of succinic acid. Each dose contained $45 \mathrm{mg}$. of iron.

Group 2.-Nine subjects. Iron absorption from a tablet containing $200 \mathrm{mg}$. of ferrous fumarate was compared with that from a similar tablet incorporating $200 \mathrm{mg}$. of succinic acid. The dose of iron was $65 \mathrm{mg}$.

Group 3.-Nine subjects. Iron absorption was compared from three different types of tablet: $200 \mathrm{mg}$. of ferrous fumarate, $185 \mathrm{mg}$. 
of ferrous sulphate, and $200 \mathrm{mg}$. of ferrous fumarate plus $500 \mathrm{mg}$ of ascorbic acid. All the tablets contained $65 \mathrm{mg}$. of iron.

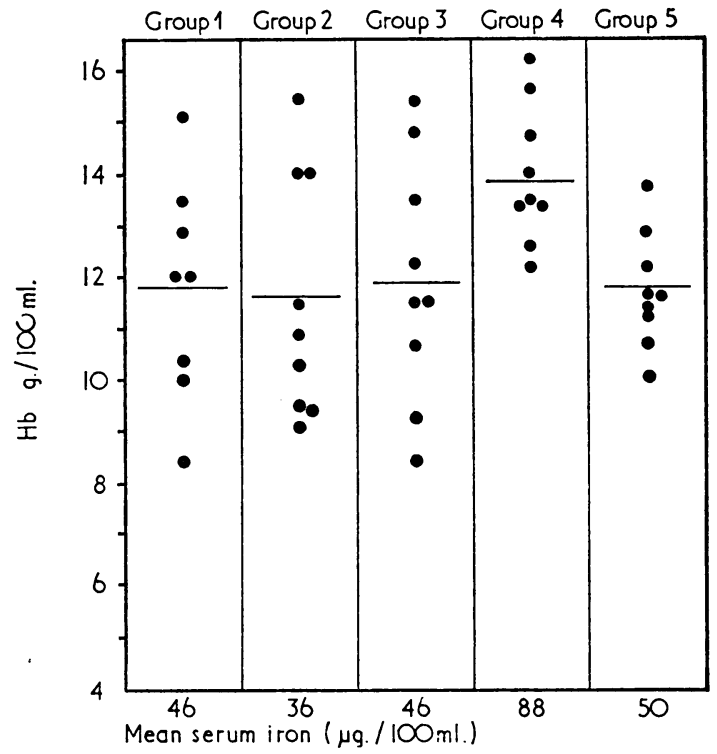

FIG. 1.-Haemoglobin values and mean serum iron in the five groups of subjects.

In these first three groups, single doses only were given of each of the substances under test. The subjects fasted for at least two hours before and two hours after each dose.

In the following two groups a multiple dose technique was used as described by Callender and Warner (1968).

Group 4.-Nine subjects. For each test one tablet was taken with a standard breakfast of two slices of bread with butter and jam and a cup of tea on three successive days. Iron absorption from tablets of ferrous sulphate was compared with that from ferrous sulphate plus $185 \mathrm{mg}$. of succinic acid. Both types of tablet contained $37 \mathrm{mg}$. of iron.

Group 5.-Nine subjects. For each test one tablet was taken on three successive days in the morning, at least half to one hour before the first meal. Iron absorption from tablets containing ferrous sulphate was compared with ferrous sulphate plus $185 \mathrm{mg}$. of succinic acid plus $245 \mathrm{mg}$. of ascorbic acid. The tablets each contained $37 \mathrm{mg}$. of iron.

\section{Results}

The results are illustrated in Figs. 2 and 3. A standard $t$ test for paired observations and a crossover test (Cochran and

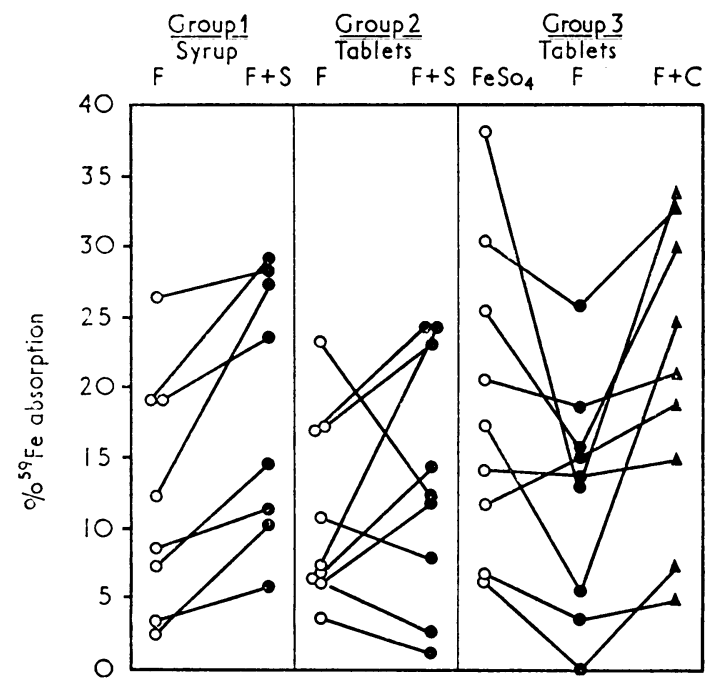

FIG. 2.-Absorption of ${ }^{89} \mathrm{Fe}$ from therapeutic preparations in groups 1,2 , and $3 . \quad F=$ Fumarate. $S=$ Succinic acid $\mathrm{C}=$ Ascorbic acid.
Cox, 1957) for the triple observations were used to examine the data. In groups 1 and 2 respectively succinic acid enhanced the absorption of iron from ferrous fumarate when the preparation was given in the form of a syrup but not as a tablet $(t=3.99, \mathrm{P}<0.01$; and $t=0.948, \mathrm{P}>0.30$ respectively).

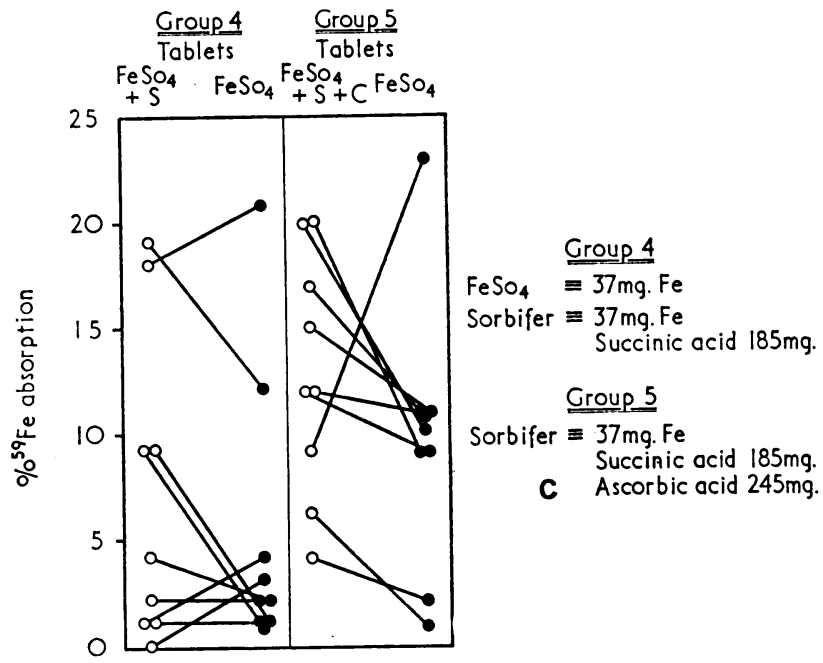

Fig. 3.-Absorption of ${ }^{80} \mathrm{Fe}$ from therapeutic preparations in groups 4 and 5. There was no statistical difference in the paired observations.

In group 3 iron from the ferrous fumarate plus ascorbic acid tablet was better absorbed than from ferrous fumarate alone but no better than iron in the ferrous sulphate tablet (using standard crossover test).

Succinic acid did not enhance absorption of iron from the ferrous sulphate tablet in group $4(t=1 \cdot 1349, \mathrm{P}>0 \cdot 2)$.

When ascorbic acid was added to the ferrous sulphate plus succinic acid eight out of nine subjects in group 5 showed an enhanced absorption of iron, but when the ninth subject, who showed a pronounced difference in the reverse direction, is included there is no statistical difference in the paired observations $(t=1 \cdot 2868, \mathrm{P}>0 \cdot 2)$.

\section{Discussion}

The results of the present investigations agree with those of Brise and Hallberg (1962) in finding an enhancing effect of succinic acid on absorption of iron when given in a liquid preparation, but not in tablet form. Hallberg and Sölvell (1966), however, investigated further the effect of succinic acid as a promoter of iron absorption from iron tablets, using a double isotope multiple-dose technique to compare the relative utilization of iron from different preparations given on alternate days for 10 days. Their subjects were blood donors who had donated blood about six times a year for a varying period of time and were all considered to be iron-deficient. From observations on a total of 80 subjects they found that both succinic acid and monosodium succinate had a significant enhancing effect on absorption of iron from ferrous sulphate.

In our studies the lack of significant effect of the succinic acid in group 4 may be because this group contained fewer iron-deficient subjects and the dose was given with a meal. This, however, does not apply to group 2 .

In group 5, where the combined effect of succinic acid and ascorbic acid was tested, eight out of nine subjects showed an enhanced absorption of ferrous sulphate. A very great difference in the reverse direction in one subject makes the results not statistically significant. If there is a real effect it clearly needs a larger group of subjects to reveal it.

The range and mean absorption of iron in terms of milligrams per dose (Fig. 4) emphasizes the very wide variation in 
absorption of iron preparations in different individuals. Thus iron from ferrous sulphate in group 3 was better absorbed than in groups 4 and 5 , even taking into consideration the larger dose of iron in group 3 (65 mg. as opposed to $37 \mathrm{mg}$.). The ferrous sulphate tablets in group 3 were supplied by a different

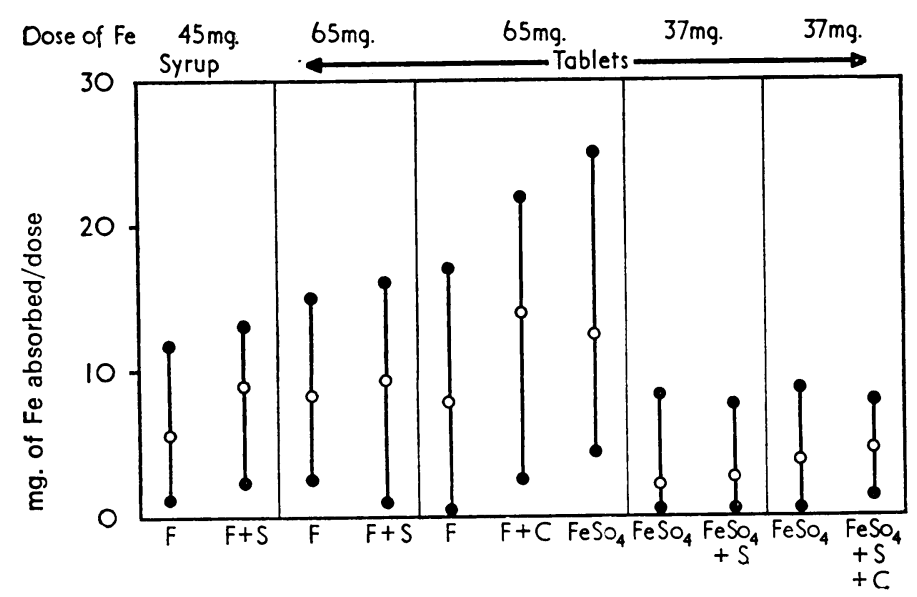

FIG. 4.-Range and mean absorption of iron in terms of milligrams per dose in all five groups of subjects.

source from groups 4 and 5, but there does not appear to be any significant difference in the preparation of the tablets. It would seem, therefore, that the greater absorption in group 3 can be accounted for only by variation in absorption between individuals within the groups.

The majority of observations on the effectiveness of different iron preparations have been made on different individuals, and for such studies to be valid it is obvious that large groups require to be studied. The use of radioactive labelled material has the advantage that it enables comparisons to be made in individual subjects.

We are indebted to the pharmaceutical firms Astra Hewlett and Glaxo Laboratories for supplies of ${ }^{50} \mathrm{Fe}$-labelled tablets. The work was supported in part by a grant from the Medical Research Council. Miss M. Alcock and Miss S. Howes provided valuable technical assistance.

\section{REFERENCES}

Brise, H., and Hallberg, L. (1962). Acta Medica Scandinavica, Suppl. No. 376, p. 59.

Callender, S. T., and Warner, G. T. (1968). American fournal of Clinical Nutrition, 21, 1170.

Callender, S. T., Witts, L. J., Warner, G. T., and Oliver, R. (1966). British fournal of Haematology, 12, 276.

Cochran, W. G., and Cox, G. M. (1957). Experimental Design, p. 127. New York, Wiley.

Hallberg, L., and Sölvell, L. (1966). Acta Medica Scandinavica, Suppl. No. 459 , p. 23.

Warner, G. T., and Oliver, R. (1966). Physics in Medicine and Biology, 11,83 .

\section{Pancreatic Calcification: A Report of 45 Cases}

\section{E. O. OLURIN,* M.B., F.R.C.S., F.R.C.S.ED. ; OYINADE OLURIN, † M.B., CH.B., D.o.}

ummary: Forty-five cases of pancreatic calcification $S$ are reported, and it is shown that in Western Nigeria this malady afflicts younger people than in Europe and the United States of America. Males and females seem about equally affected in Western Nigeria, whereas it predominantly affects males in France, Britain, and North America. Diabetes mellitus was the commonest complication in this series, and brought many patients to the doctor. In this series chronic relapsing pancreatitis was a rare cause; there was no history of alcoholism; and protein malnutrition was thought to be responsible for pancreatic calcification in over $\mathbf{9 0 \%}$ of the patients.

\section{Introduction}

Clinical pancreatic calcification is usually diagnosed radiologically in the routine investigation of its complications and sometimes as an incidental finding in the radiological investigation of upper abdominal pain. Graaf $^{1}$ was reported to have first recorded pancreatic calculi in 1667. Haggard and Kirtley ${ }^{2}$ in 1936 collected 204 cases from the literature covering a period of 201 years. Since that comprehensive review there have been a number of smaller reviews and case reports. Authors in the United States of America include Gillies, ${ }^{3}$ King and Waghelstein, ${ }^{4}$ Lionello, Ficarra, and Ryan, ${ }^{5}$ Mayo, ${ }^{6}$ Martin and Canseco, ${ }^{7}$ Wirts and Snape, ${ }^{8}$ Domzalski, ${ }^{9}$ Gambill and Pugh, ${ }^{11}$ Edmondson, Bullock, and Mehl, ${ }^{11}$ and Kneidel. ${ }^{12}$ Recently, important contributions have been made by Howat ${ }^{1314}$ and Pollock $^{15}$ in Great Britain, by Sarles et al. ${ }^{16}$ in France, and by Marks and Bank ${ }^{17}$ of South Africa. Pancreatic calcifications have also been reported from some tropical countries: Zuidema $^{18} 19$ in Indonesia, Mahadevan ${ }^{20}$ and Ratnaike and Rajasuriya ${ }^{21}$ in India, Shaper ${ }^{22}$ and Banwell et al..$^{23}$ in Uganda, and Kinnear ${ }^{24}$ in Nigeria.

There seem to be pronounced differences in the clinical features and aetiology of pancreatic calcification as obtain in Western Europe and the. United States of America on the one hand and in the tropical countries on the other. The aim of this paper is to analyse 45 cases of pancreatic calcification seen in University College Hospital, Ibadan, and to illustrate the similarities and differences in their features as compared with cases reported in other countries. We shall not differentiate between pancreatic calculi, so-called pancreatic lithiasis, and disseminated pancreatic calcification, because it is usually impossible to differentiate between the two types clinically, radiologically, and pathologically. In nearly all cases both types coexist in the same pancreas. Indeed, as $\mathrm{King}^{25}$ said, a single or several large calculi confined to the ducts are generally the exception. Like Gambill and Pugh, ${ }^{10}$ we use the term "pancreatic calcification" to denote calcareous deposits in any 